\title{
NF-kB-mediated inhibition of microRNA-149-5p regulates Chitinase-3-like 1 expression in human airway epithelial cells
}

Citation for published version (APA):

Huebner, K., Karwelat, D., Pietsch, E., Beinborn, I., Winterberg, S., Bedenbender, K., Benedikter, B. J., Schmeck, B., \& Vollmeister, E. (2020). NF-kB-mediated inhibition of microRNA-149-5p regulates Chitinase-3-like 1 expression in human airway epithelial cells. Cellular Signalling, 67, [109498]. https://doi.org/10.1016/j.cellsig.2019.109498

Document status and date:

Published: 01/03/2020

DOI:

10.1016/j.cellsig.2019.109498

Document Version:

Publisher's PDF, also known as Version of record

Document license:

Taverne

Please check the document version of this publication:

- A submitted manuscript is the version of the article upon submission and before peer-review. There can be important differences between the submitted version and the official published version of record.

People interested in the research are advised to contact the author for the final version of the publication, or visit the DOI to the publisher's website.

- The final author version and the galley proof are versions of the publication after peer review.

- The final published version features the final layout of the paper including the volume, issue and page numbers.

Link to publication

\footnotetext{
General rights rights.

- You may freely distribute the URL identifying the publication in the public portal. please follow below link for the End User Agreement:

www.umlib.nl/taverne-license

Take down policy

If you believe that this document breaches copyright please contact us at:

repository@maastrichtuniversity.nl

providing details and we will investigate your claim.
}

Copyright and moral rights for the publications made accessible in the public portal are retained by the authors and/or other copyright owners and it is a condition of accessing publications that users recognise and abide by the legal requirements associated with these

- Users may download and print one copy of any publication from the public portal for the purpose of private study or research.

- You may not further distribute the material or use it for any profit-making activity or commercial gain

If the publication is distributed under the terms of Article $25 \mathrm{fa}$ of the Dutch Copyright Act, indicated by the "Taverne" license above, 
Research Article

\title{
NF-кB-mediated inhibition of microRNA-149-5p regulates Chitinase-3-like 1 expression in human airway epithelial cells
}

\author{
Kathleen Hübner ${ }^{\mathrm{a}}$, Diana Karwelat ${ }^{\mathrm{a}, 1}$, Emma Pietsch ${ }^{\mathrm{a}, 2}$, Isabell Beinborn ${ }^{\mathrm{a}}$, Sarah Winterberg ${ }^{\mathrm{a}, 3}$, \\ Katrin Bedenbender ${ }^{\mathrm{a}}$, Birke J. Benedikter ${ }^{\mathrm{a}, \mathrm{b}}$, Bernd Schmeck ${ }^{\mathrm{a}, \mathrm{c}, * *}$, Evelyn Vollmeister ${ }^{\mathrm{a}, *}$ \\ ${ }^{a}$ Institute for Lung Research, Universities of Giessen and Marburg Lung Center, Hans-Meerwein Straße 2, 35043 Marburg, Hesse, Germany \\ ${ }^{\mathrm{b}}$ Department of Medical Microbiology, NUTRIM School of Nutrition and Translational Research in Metabolism, Maastricht University Medical Center, PO box 5800, \\ 6202AZ Maastricht, the Netherlands \\ ${ }^{\mathrm{c}}$ Department of Pulmonary and Critical Care Medicine, University Medical Center Marburg, Universities of Giessen and Marburg Lung Center, Philipps-University Marburg, \\ Member of the German Center for Lung Research (DZL), Hans-Meerwein Straße 2, 35043 Marburg, Hesse, Germany
}

\section{A R T I C L E I N F O}

\section{Keywords:}

CHI3L1

miR-149-5p

Airway epithelial cell

Toll-like receptor

Pneumonia

$\mathrm{NF}-\mathrm{KB}$

\begin{abstract}
A B S T R A C T
Lower respiratory tract infections are among the most common causes of death worldwide. Main pathogens leading to these severe infections are viruses and gram-positive bacteria that activate toll-like receptor (TLR)mediated immune responses via pathogen-associated molecular patterns. One protective factor induced during infection is Chitinase-3-like 1 (CHI3L1), which exerts various functions, e.g. in host cell proliferation and bacterial counteraction, and has been proposed as a biomarker in several acute and chronic inflammatory conditions. MicroRNAs (miR) have become important regulators of inflammation and infection and are considered therapeutic targets in recent years. However, it is not known whether microRNAs play a role in the regulation of CHI3L1 expression in TLR-mediated respiratory epithelial cell inflammation. In this study, we analysed the preand post-transcriptional regulation of CHI3L1 by TLRs in bronchial epithelial cells. Therefore, we stimulated BEAS-2B cells with the bacterial TLR2-ligand lipoteichoic acid or the viral dsRNA analogue poly(I:C). We observed an increase in the expression of CHI3L1, which was dependent on TNF- $\alpha$-mediated NF- $\mathrm{KB}$ activation in TLR2- and TLR3-activated cells. Moreover, TLR2 and - 3 stimulation caused downregulation of the microRNA miR-149-5p, an effect that could be suppressed by inhibiting NF- $\mathrm{kB}$ translocation into the nucleus. Luciferase reporter assays identified a direct interaction of miR-149-5p with the CHI3L1 3'untranslated region. This interaction was confirmed by inhibition and overexpression of miR-149-5p in BEAS-2B cells, which altered the expression levels of CHI3L1 mRNA. In summary, miR-149-5p directly regulates CHI3L1 in context of TLRmediated airway epithelial cell inflammation and may be a potential therapeutic target in inflammation and other diseases.
\end{abstract}

\section{Introduction}

Pulmonary infections such as pneumonia are among the leading causes of deaths worldwide. Major causative pathogens are gram- positive Streptococcus pneumoniae (S. pneumoniae) or Influenza A Virus [1,2]. During infection epithelial cells recognize pathogen-associated molecular patterns (PAMPs) via pattern recognition receptors such as toll-like receptors (TLRs) and orchestrate the inflammatory host

\footnotetext{
Abbreviations: ANOVA, analysis of variance; CHI3L1, chitinase-3-like 1; CTR, control; DAPI, 4 ,6-diamidino-2-phenylindol; fwd, forward; DMSO, dimethyl sulf-

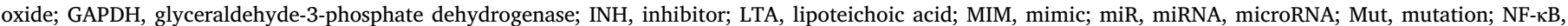

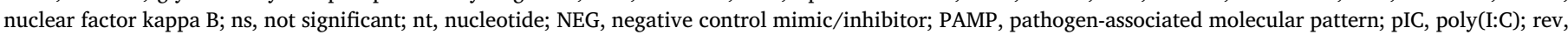
reverse; TLR, toll-like receptor; TNF- $\alpha$, tumour necrosis factor alpha; UTR, untranslated region; WT, wildtype

* Correspondence to: E Vollmeister, Institute for Lung Research, Philipps University Marburg, Hans-Meerwein Straße 2, 35043 Marburg, Hesse, Germany.

** Correspondence to: B Schmeck, Institute for Lung Research, Universities of Giessen and Marburg Lung Center, Member of the German Center for Lung Research, Hans-Meerwein Straße 2, 35043 Marburg, Hesse, Germany.

E-mail addresses: bernd.schmeck@uni-marburg.de (B. Schmeck), evelyn.vollmeister@uni-marburg.de (E. Vollmeister).

${ }^{1}$ Present address: Bayer AG, Pharmaceuticals, Mechanistic Toxicology, Müllerstraße 178, 13353 D-Berlin.

${ }^{2}$ Present address: Bernhard Nocht Institute for Tropical Medicine, Parasitology Section, Bernhard-Nocht-Straße 74, D-20359 Hamburg, Germany.

${ }^{3}$ Present address: Department of Molecular Neurosciences, Institute of Anatomy and Cell Biology, Philipps-University, Marburg, Hesse, Germany.
} 
response [3]. Important PAMPs are e.g. lipoteichoic acid (LTA) and RNA or DNA from bacteria and viruses that specifically activate certain TLR signalling cascades [4-6]. LTA from gram-positive Staphylococcus aureus (S. aureus) activates TLR2 complexes [7]. After ligand recognition, TLR2 signals via MyD88 (Myeloid Differentiation Primary Response 88), IRAK1 (Interleukin 1 Receptor Associated Kinase 1) and TRAF6 (TNF Receptor Associated Factor 6) to IKK (IкB kinase) protein kinase complex [8]. Here, ІкВ $\alpha$ (Nuclear Factor of kappa light polypeptide gene enhancer in B-cells inhibitor, alpha) is phosphorylated and degraded enabling the translocation of NF-KB (Nuclear Factor kappa B) to the nucleus [9]. Subsequently, NF- $\mathrm{KB}$ induces expression of pro-inflammatory cytokines such as CXCL8 (C-X-C Motif Chemokine Ligand 8 ) and IL-1 $\beta$ (Interleukin 1 Beta). In contrast to bacterial PAMPs, viral dsRNA mimic polyinosinic:polycytidylic acid (poly(I:C)) is recognized by TLR3 [10], which directly interacts with TRIF (TICAM1, Toll Like Receptor Adaptor Molecule 1). Thereby, it can activate either IRF3 (Interferon Regulatory Factor 3) via TBK1 (TANK Binding Kinase 1) to mount an IFN- $\beta$ (IFNB1, interferon beta 1 ) response or NF-kB via RIPK1 (Receptor Interacting Serine/Threonine Kinase 1) and IKK to induce the expression of pro-inflammatory cytokines as for TLR2 [11].

Chitinase-3-like 1 (CHI3L1) is an important NF-kB-dependent host factor and a biomarker for both, acute and chronic inflammation [12-16]. CHI3L1 is a chitinase-like protein with a glycosyl hydrolase 18 domain which, unlike real chitinases, can bind chitin but cannot cleave it due to amino acid modifications in the catalytic domain [17]. In a cellular context, CHI3L1 protein is involved in several processes, for instance proliferation, adhesion and cell migration, and is secreted by different cell types including colonic epithelial cells [18-21]. Additionally, CHI3L1 is involved in repair of epithelium and in bacterial counteraction [19,22-25]. In this regard, CHI3L1 knockout mice were more sensitive to $S$. pneumoniae infection compared to wildtype mice [23].

MicroRNAs (miRNAs or miRs) are small, non-coding RNAs with a length of 21 to 23 base pairs [26,27]. They are transcribed as primiRNAs in the nucleus, processed to pre-miRNAs and subsequently exported into the cytoplasm where they are cleaved [28-32]. The mature miRNA binds mainly to 3 untranslated regions (UTR) of its target mRNAs with its corresponding seed region at nucleotide position 2 to 8 . MiRNA function is coupled to post-transcriptional regulation such as mRNA stability or translational enhancement [33-35]. In the last decades, miRNA function was demonstrated to be important in various diseases such as diverse cancers, chronic inflammation, as observed in chronic obstructive pulmonary disease or asthma, and acute inflammation after infection. For instance, in lipopolysaccharide induced acute inflammation the expression of miR-146a is activated in human monocytes through NF- $\mathrm{KB}$ and downregulates IRAK1 acting as an antiinflammatory miRNA [36]. In Hepatitis C Virus infection in hepatocytes, NOTCH1 (Notch receptor 1 ) is post-transcriptionally regulated by miR-449a [37]. Thereby, NOTCH1 induces TNF- $\alpha$-mediated NF-kB activation and stimulates CHI3L1 expression. In osteomyelitis caused by Staphylococcus aureus, miR-24 was identified to regulate CHI3L1 expression by binding to its 3` UTR [38]. Additionally, miR-24 suppresses CHI3L1 expression during $S$. aureus-induced macrophage polarization [39]. Besides miR-24/CHI3L1 miRNA-target interaction, little is known regarding miRNA-mediated regulation of CHI3L1.

In this study, we wanted to elucidate how the expression pattern of CHI3L1 is influenced upon TLR2 and TLR3 activation in human bronchial epithelial cells and whether miRNAs (miR-24-3p, miR-30d, miR125a-3p, miR-149-5p) are involved in its regulation. We used ligand stimulations to activate TLR2 and TLR3 signalling and investigated the involved signalling pathway, tested miRNA/mRNA interaction using the luciferase reporter assay, and overexpressed or inhibited putative miRNAs in host cells to explore the direct influence on CHI3L1 expression. Our study contributes to the understanding of the post-transcriptional regulation of CHI3L1 and thus provides starting points for therapeutic purposes in the fight against inflammation.

\section{Material and methods}

\subsection{Cell culture, stimulation and inhibitor treatments}

Human bronchial epithelial BEAS-2B cells were purchased from ATCC $^{\circledast}$ (CRL-9609 ${ }^{\mathrm{TM}}$ ) and cultured as described in manufacturer's instructions with following exceptions. Supplement GA-1000 of BEBM Supplements (CC-4175, Lonza) was not used and flasks were not coated. Cells were cultured at $37{ }^{\circ} \mathrm{C}$ and $5 \% \mathrm{CO}_{2}$. For stimulation experiments, $1.5 * 10^{5}$ BEAS-2B cells were seeded per 12 well. After $48 \mathrm{~h}$ cells were treated with indicated amounts of human recombinant TNFa (R\&D Systems), or purified lipoteichoic acid (LTA) from Staphylococcus aureus (InvivoGen; TLR2 ligand) or poly(I:C) (InvivoGen; TLR3 ligand) for $24 \mathrm{~h}$. RNA samples (quantitative RT-PCR) or supernatants (ELISA) were collected. For immunofluorescence staining, cells were stimulated with LTA for $2 \mathrm{~h}$ or poly(I:C) for $4 \mathrm{~h}$. Please note that the commercially available LTA from $S$. aureus, which we used in this study, was shown to be contaminated with lipopeptide that is responsible for TLR2 activation [40]. For inhibitor experiments, BEAS-2B cells were pre-treated with $5 \mu \mathrm{M}$ BAY11-7082 (Merck Millipore) dissolved in dimethyl sulfoxide (DMSO, Carl Roth GmbH + Co. KG) for $1 \mathrm{~h}$ before stimulation.

The human lung epithelial cell line A549 was purchased from ATCC $^{\circledast}$ (CCL-185) and cultured in Ham's F-12 Nutrient Mix, GlutaMAX ${ }^{\text {TM }}$ Supplement (Thermo Fisher Scientific) supplemented with $10 \%$ fetal calf serum (FCS superior, Biochrom GmbH). Cells were cultured at $37^{\circ} \mathrm{C}$ and $5 \% \mathrm{CO}_{2}$.

\subsection{Transfection of miRNA mimic and inhibitor}

For mirVana ${ }^{\mathrm{TM}}$ miRNA inhibitor or mimic transfection, $1.2 * 10^{5}$ BEAS-2B cells or $1.5 * 10^{5}$ A549 cells per 24 well were reverse transfected with $10 \mathrm{pmol}$ inhibitor or mimic for miR-149-5p (MIMAT0000450; MH12788, MC12788) as well as mirVana ${ }^{\mathrm{TM}}$ miRNA inhibitor and mirVana ${ }^{\mathrm{TM}}$ miRNA mimic negative control \#1 (NEG) by Lipofectamine $^{\mathrm{TM}}$ RNAiMax (Thermo Fisher Scientific) according to manufacturer's instructions using Opti-MEM ${ }^{\mathrm{TM}}$ (Thermo Fisher Scientific). If indicated, cells were mock- or LTA-stimulated after $18 \mathrm{~h}$ of transfection for additional $24 \mathrm{~h}$.

\subsection{Generation of vectors}

To generate a CHI3L1 3'UTR wildtype (3'UTR CHI3L1 WT) containing vector for luciferase reporter assay, genomic DNA from BEAS$2 \mathrm{~B}$ cells was used as a template in PCR reaction. The insert was amplified by hCHI3L1_3'UTR forward (fwd, 5' CGACTCGAGCCCTCTGTT CTGCACACAGC $3^{\prime}$ ) and reverse primers (rev, 5' CGAGCGGCCGCCAC TGTTAAGCTCTTGTAC 3'; Metabion International AG) that contain $\underline{X h o I}$ and NotI restriction sites (underlined, New England Biolabs), respectively, for integration into the vector backbone psiCHECK $^{\mathrm{TM}}-2$ multiple cloning site (Promega). For generating mutations in seed sequences of respective miRNAs, we synthesized mutated CHI3L1 3'UTR fragments with restriction sites XhoI and NotI (gBlocks $^{\circledR}$ Gene Fragments, Integrated DNA Technologies, Inc.) and integrated them into psiCHECK ${ }^{\mathrm{TM}}-2$ vector. All vectors were ligated with T4 DNA Ligase following manufacturer's instructions (New England Biolabs), transformed into TOP10 E. coli and plated on LB agar (Carl Roth GmbH + Co KG) plates containing $100 \mu \mathrm{g} / \mathrm{mL}$ ampicillin (Carl Roth $\mathrm{GmbH}+\mathrm{Co}$ KG) for selection. All generated vectors were confirmed by sequencing (Sequencing Service, LMU Munich).

\subsection{Luciferase reporter assay}

Dual-Glo ${ }^{\circledR}$ Luciferase Reporter Assay (Promega) was used as described in manufacturer's instructions with following modifications. A549 cells $\left(1.5 * 10^{5}\right)$ were reverse transfected with Lipofectamine 2000 
(Thermo Fisher Scientific) in a 24well format using $200 \mathrm{ng}$ vector and 10 pmol miRNA mimic. PsiCHECK ${ }^{\mathrm{TM}}-2$ served as empty vector control. Measurements of luciferase luminescence were performed $48 \mathrm{~h}$ post transfection using Tecan Infinite ${ }^{\circledast}$ M200 PRO plate reader (Tecan). The relative luciferase activity was presented as the relative response ratio of the firefly luciferase as a transfection control and Renilla luciferase. Normalization was calculated using A549 cells transfected with empty vector control and miRNA mimic negative control.

\subsection{RNA extraction and quantitative reverse-transcription polymerase chain reaction ( $R T-P C R)$}

Total RNA from cells was extracted by phenol-chloroform based method using Isol-RNA Lysis Reagent (5`Prime, Hamburg, Germany) according to the manufacturer's instructions. RNA was reverse transcribed using either TaqMan MicroRNA Reverse Transcription Kit or High-Capacity RNA-to-cDNA kit following manufacturer's instructions (Thermo Fisher Scientific), followed by quantitative RT-PCR with ViiA7 $^{\mathrm{TM}}$ System and QuantStudio $^{\mathrm{TM}}$ Design \& Analysis Software v1.3.1 (Thermo Fisher Scientific) according to manufacturer's instructions. MicroRNAs were quantified using TaqMan Fast Advanced Master Mix (miR-146a-5p ID000468, miR-149-5p ID002255, miR-24-3p ID000402, RNU48 ID001006, Thermo Fisher Scientific). Expression of mRNAs were quantified using Fast SYBR ${ }^{\mathrm{TM}}$ Green Master Mix (Thermo Fisher Scientific) or Luna ${ }^{\circledR}$ Universal qPCR Master Mix (New England Biolabs) together with specific primer pairs (CHI3L1 fwd 5` CTGGTGCTGCTCC AGTGC 3`, rev 5`GAAGCGGTCAAGGGCATCT 3`; CXCL8 fwd 5`ACT GAGAGTGATTGAGAGTGGAC 3`, rev 5`AACCCTCTGCACCCAGTTTTC 3`; TNF- $\alpha$ fwd 5` GCTGCACTTTGGAGTGATCG 3`, rev 5`TCACTCGG GGTTCGAGAAGA 3`; GAPDH fwd 5` CCACATCGCTCAGACACCAT 3`, rev 5`CGCAACAATATCCACTTTACCAGAG 3`; Metabion International AG). The $x$-fold expression was calculated using the $2^{-\Delta \Delta \mathrm{ct}}$ method and quantitative RT-PCR results were normalized to the corresponding control cells [41].

\subsection{Enzyme-linked Immunosorbent assay (ELISA)}

Protein release of CHI3L1 in the supernatants of stimulated BEAS-2B cells was analysed using Human Chitinase-3-like 1 DuoSet ELISA according to manufacturer's instructions (R\&D systems, Inc.). All measurements were performed in duplicates using Tecan Infinite ${ }^{\circledast}$ M200 PRO plate reader (Tecan).

\subsection{Immunofluorescence}

BEAS-2B cells were seeded with $3.5 * 10^{4}$ cells on sterile glass cover slips in 24well plates for $72 \mathrm{~h}$. After treatment or stimulation cover slips underwent three washing steps with $1 \times$ PBS (GE Healthcare Life Science) followed by fixation with $4 \%$ paraformaldehyde (Carl Roth $\mathrm{GmbH}+$ Co. KG) for $10 \mathrm{~min}$ at room temperature. For intracellular protein detection, cells were permeabilized with $0.1 \%$ Triton X-100 (Carl Roth $\mathrm{GmbH}+$ Co. KG) in $1 \times$ PBS for 10 min followed by three washing steps with $1 \times$ PBS. Primary antibody (anti-p65-rabbit-IgG, Santa Cruz Biotechnology) diluted 1:50 in 0.35\% BSA/PBS (fraction V, Carl Roth $\mathrm{GmbH}+$ Co. KG) was added and incubated in a humidified chamber for $2 \mathrm{~h}$ at room temperature. After additional three washing steps cells were incubated with secondary antibody (goat anti-rabbit IgG, Alexa-Fluor ${ }^{\circledast}$ 555, Thermo Fisher Scientific) followed by three washing steps. Consecutively, cells were stained for nucleic acids with DAPI (4',6-Diamidino-2-phenylindol, ATT Bioquest, dilution 1:5000 in ultrapure $\mathrm{H}_{2} \mathrm{O}$, Biochrom) for $10 \mathrm{~min}$ and Phalloidin (Alexa Fluor 488, Thermo Fisher Scientific) as described in manufacturer's protocol. Cells were washed twice with water, mounted with Mowiol (4-88, Carl Roth $\mathrm{GmbH}+\mathrm{Co}$. KG) on a slide and dried overnight at $4{ }^{\circ} \mathrm{C}$ prior to microscopy with Axio Vert A1 and Axio Cam MRm (Carl Zeiss, Jena, Germany), Kübler codix HXP120C and Axio Vision SE64 Rel.4.8.
Overlay images were generated using Image J (Fiji, Version 2).

\subsection{Statistical analysis}

Significance was statistically evaluated using the indicated analysis tools provided by GraphPad PRISM 6 software (San Diego, CA). $\log _{2^{-}}$ transformed data were used for quantitative RT-PCR fold changes and ELISA analysis. $P$ values of $<0.05$ were considered statistically significant.

\section{Results}

\subsection{TLR2 and TLR3 activation induce CHI3L1 expression in an NF-KB dependent manner in BEAS-2B cells}

To examine the expression of CHI3L1 during bacterial and viral infection of the respiratory epithelium, we first investigated the expression of CHI3L1 mRNA and protein in a setting similar to respiratory infections in TLR2- and TLR3-activated human bronchial epithelial cells. Therefore, we stimulated the bronchial epithelial cell line BEAS2B with two different TLR activators, namely $S$. aureus lipoteichoic acid (LTA, [42]), and a virus-like stimulus poly(I:C) (pIC, [43]). As a control for inflammatory response upon TLR2 and -3 activation, we observed significant increases in CXCL8 mRNA and protein expression (Suppl. Fig. S1). Compared to mock-treated control cells, both, LTA and poly (I:C)-treated cells showed significant increases in CHI3L1 mRNA expression and protein release into the medium (Fig. 1). In particular, LTA treatment resulted in a 20 -fold and 3 -fold increase of CHI3L1 mRNA expression and protein release, respectively (Fig. 1A, B). In addition, we investigated a second TLR2 agonist, Pam3CSK4, and obtained similar results as seen for LTA stimulation experiments (Suppl. Fig. S2). For poly(I:C), we observed an 8-fold induction of mRNA expression and a 2.5-fold increase in CHI3L1 protein release (Fig. 1C, D). Thus, CHI3L1 expression is strongly upregulated in bronchial epithelial cells following TLR2 and TLR3 activation.

CHI3L1 expression in hepatocytes is regulated by TNF- $\alpha$, as revealed by Sarma et al. (2012) [37]. Therefore, we analysed how LTA and poly(I:C) influence the expression of TNF- $\alpha$ mRNA in bronchial epithelial cells and how TNF- $\alpha$ stimulation in turn affects CHI3L1 expression. In both stimulation experiments, TNF- $\alpha$ mRNA expression was induced up to 40-fold by both concentrations of LTA and the highest concentration of poly(I:C) (Fig. 2A, B). Consistently, stimulation of BEAS-2B cells with TNF- $\alpha$ resulted in an up to 12 -fold induction of CHI3L1 mRNA expression and a 3-fold increase in protein release compared to mock-treated cells (Fig. 2C, D).

To determine, which signalling pathway is involved in CHI3L1 mRNA and protein expression, we tested different inhibitors to block p38/MAPK (SB202190), ERK1/2 (U0126), TAK1 (5Z-7-Oxozeanol) as well as TNF- $\alpha$-mediated phosphorylation of IKB $\alpha$ (BAY11-7082) for subsequent inhibition of NF- $\mathrm{KB}$ translocation to the nucleus [44], and stimulated these BEAS-2B cells with poly(I:C) or LTA. Cytotoxicity analysis revealed $>95 \%$ viable cells in all treatments (Suppl. Fig. S3A). As a control we tested CXCL8 mRNA expression and observed an expected and strong decrease in TAK1-inhibited cells upon poly(I:C) and LTA stimulation and in BAY11-7082-inhibited cells upon poly(I:C) stimulation compared to DMSO-treated control cells (Suppl. Fig. S3B). Additionally, we investigated NF- $\mathrm{kB}$ translocation to the nucleus, which can be blocked by BAY11-7082, by immunofluorescence microscopy using anti-p65 for NF-kB detection (Fig. 3A). In mock-treated BEAS-2B cells, p65 was mainly located in the cytosol whereas, upon TLR2 or TLR3 activation, p65 was mainly translocated to the nucleus as expected. After inhibition of TNF- $\alpha$-mediated IкB $\alpha$-phosphorylation by BAY11-7082, nuclear translocation of NF- $\mathrm{KB}$ was blocked in both, mock-treated and stimulated cells.

While p38/MAPK and ERK1/2 inhibition did not change CHI3L1 mRNA and protein expression upon stimulation with poly(I:C) or LTA 
A

CHI3L1

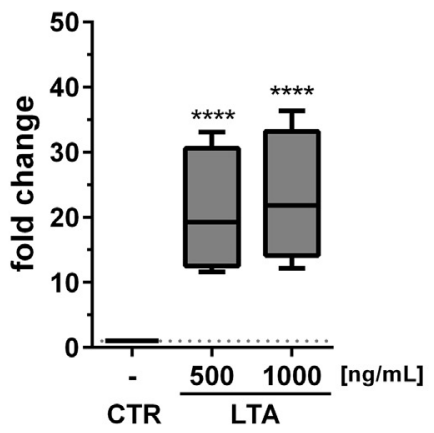

C

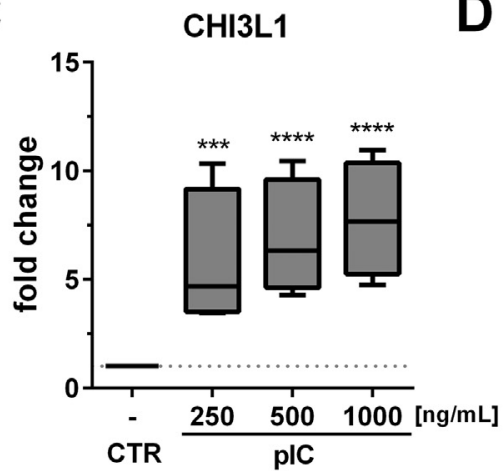

B

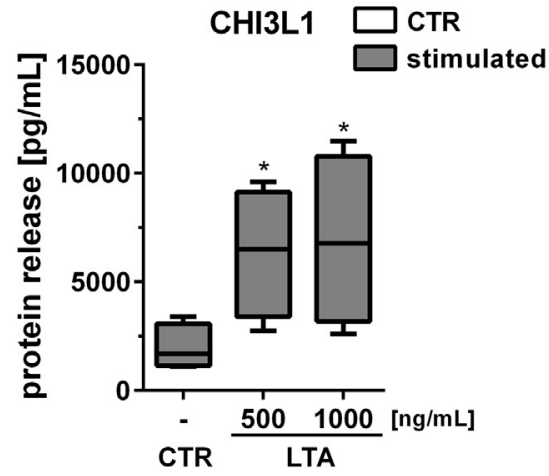

CHI3L1

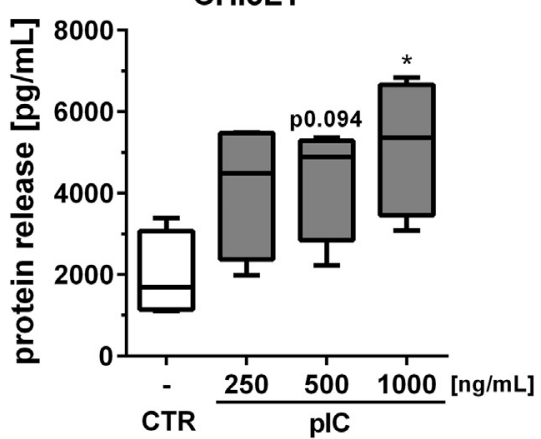

Fig. 1. CHI3L1 mRNA levels and protein release are increased upon TLR2 and TLR3 activation in BEAS-2B cells. (A, B) BEAS-2B cells were stimulated with indicated concentrations of lipoteichoic acid (LTA) from $S$. aureus or left untreated as a control (CTR). (A) Quantitative RT-PCR for CHI3L1 mRNA expression. (B) ELISA for CHI3L1 protein quantification. (C, D) BEAS-2B cells were stimulated with indicated concentrations of poly(I:C) (pIC) or left untreated as control. (C) Quantitative RT-PCR for CHI3L1 mRNA expression. (D) ELISA for CHI3L1 protein quantification. Expression of mRNA was normalized to endogenous GAPDH expression and unstimulated control. $N=4$. Stats were calculated using $\log _{2^{-}}$ transformed data. Ordinary one-way ANOVA using HolmSidak multiple comparisons test. ${ }^{*} p<.05$; $* * * p<.001$; $* * * * p<.0001$. Shown are whisker plots (whisker at min/ $\max )$.
(Suppl. Fig. S3C, D), TAK1 inhibitor and BAY11-7082-treated cells significantly reduced $\mathrm{CHI} 3 \mathrm{~L} 1 \mathrm{mRNA}$ expression and protein release to about $50 \%$ in LTA and poly(I:C)-stimulated BEAS-2B cells compared to mock-treated cells (Fig. 3B-D, Suppl. Fig. 3C, D).

In summary, CHI3L1 expression is induced upon TLR2 and TLR3 activation and can be suppressed by blocking TAK1 signalling pathway or TNF- $\alpha$-mediated NF- $\mathrm{KB}$ translocation to the nucleus in human bronchial epithelial cells.

3.2. TLR2 and TLR3 activation cause NF-KB-dependent downregulation of miRNA-149-5p in BEAS-2B cells

MicroRNAs are known as important regulators of mRNA targets in infectious diseases. Based on different miRNA-target prediction

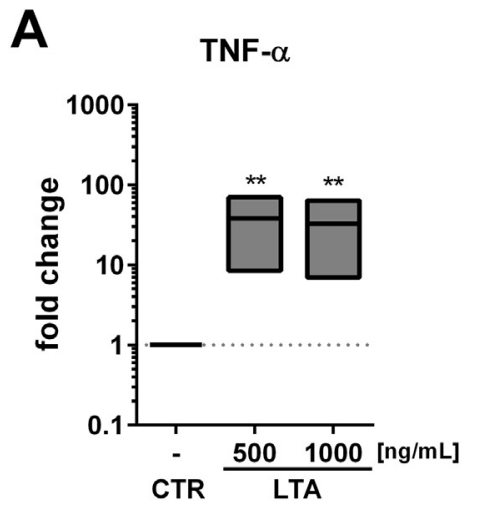

C

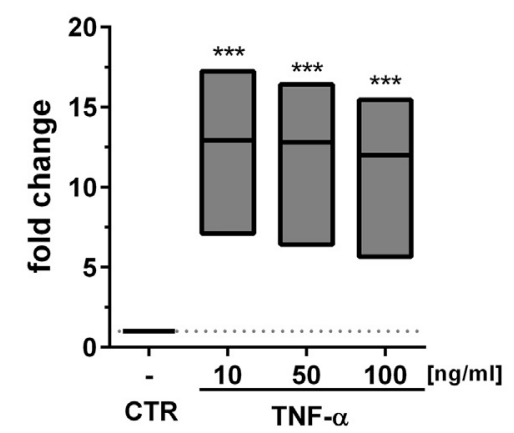

B

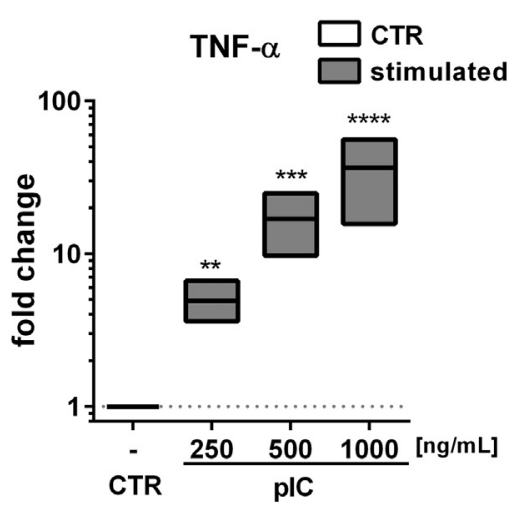

D

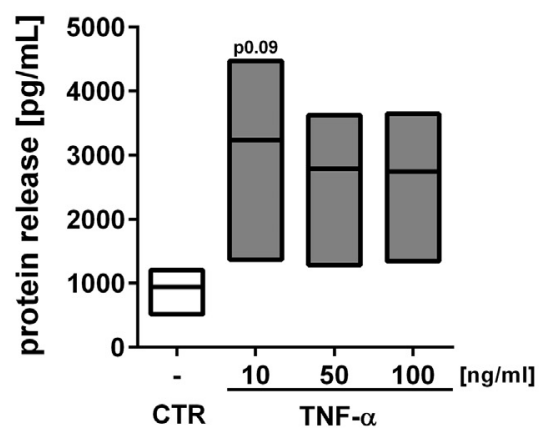

Fig. 2. TLR-mediated TNF- $\alpha$ induction increases CHI3L1 expression in BEAS-2B cells. (A, B) Quantitative RT-PCR for TNF- $\alpha$ expression in LTA or pIC stimulated BEAS-2B cells using indicated concentrations for $24 \mathrm{~h}$. (C, D) BEAS-2B cells were stimulated with indicated concentrations of TNF- $\alpha$ for 24 h. (C) Quantitative RT-PCR for CHI3L1 mRNA expression. Expression was normalized to endogenous GAPDH expression and unstimulated control. (D) ELISA for CHI3L1 quantification. $N \geq 3$. Stats were calculated using $\log _{2}$-transformed data. Ordinary one-way ANOVA using Holm-Sidak multiple comparisons test. $* p<.05 ; \quad * * p<.01 ; \quad * * * p<.001$; $* * * * p<.0001$. CTR, untreated control. Shown are floating bars with line at mean. 

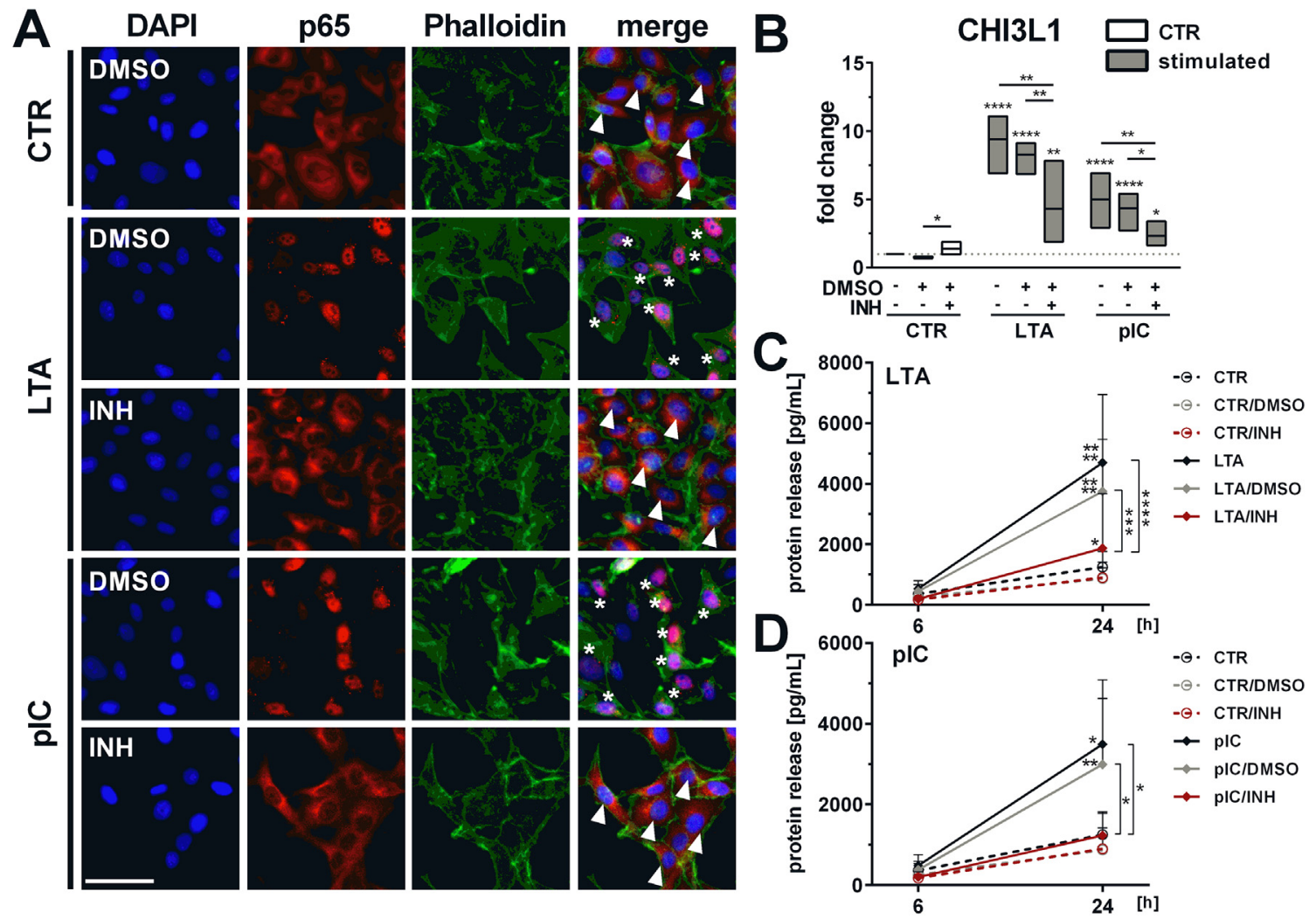

Fig. 3. Inhibition of TNF- $\alpha$-mediated p65 translocation to the nucleus reduces CHI3L1 expression upon TLR activation. (A) BEAS-2B cells were pre-treated with dimethyl sulfoxide (DMSO; $0.005 \%)$ or BAY11-7082 $(5 \mu \mathrm{M}$, INH) for $1 \mathrm{~h}$ prior to LTA $(1 \mu \mathrm{g} / \mathrm{mL})$ or pIC $(1 \mu \mathrm{g} / \mathrm{mL})$ stimulation for $2 \mathrm{~h}$ or $4 \mathrm{~h}$, respectively, or left untreated as control (CTR). Subsequent fixed samples were immuno-stained with 4',6-Diamidin-2-phenylindol (DAPI; blue; nuclei stain), anti-p65 (red) or antiPhalloidin (green; F-actin stain). Right column represents the overlay (merge). Arrows indicate examples of no nucleus translocation; asterisks indicate examples of p65 nucleus translocation. Representative sections are shown. Scale bar $=50 \mu \mathrm{m}$. (B) Quantitative RT-PCR for CHI3L1 mRNA expression in BEAS-2B cells pre-treated with DMSO $(0.005 \%)$ or BAY11-7082 $(5 \mu \mathrm{M}$, INH) for $1 \mathrm{~h}$ prior to LTA $(1 \mu \mathrm{g} / \mathrm{mL})$ or pIC $(1 \mu \mathrm{g} / \mathrm{mL})$ stimulation for $24 \mathrm{~h}$ or left untreated as a control. Expression of mRNA was normalized to endogenous GAPDH expression and unstimulated control. Shown are floating bars with line at mean. (C, D) ELISA for quantification of CHI3L1 protein release. BEAS-2B cells were pre-treated with DMSO $(0.005 \%)$ or BAY11-7082 $(5 \mu \mathrm{M}$, INH) for $1 \mathrm{~h}$ prior to LTA $(1 \mu \mathrm{g} / \mathrm{mL})$ or pIC $(1 \mu \mathrm{g} / \mathrm{mL}) \mathrm{sti}-$ mulation for $6 \mathrm{~h}$ and $24 \mathrm{~h}$ or left untreated as a control. Shown are mean values $+\mathrm{SD} . N=3$. Stats were calculated using $\log _{2}$-transformed data. Two-way ANOVA using Holm-Sidak multiple comparisons test. ${ }^{*} p<.05 ;{ }^{* *} p<.01 ;{ }^{* * *} p<.001 ; * * * p<.0001$. (For interpretation of the references to colour in this figure legend, the reader is referred to the web version of this article.)

databases, we found that miRNAs miR-24-3p, miR-30d, miR-125a-3p and miR-149-5p were predicted to bind in the 3 ' UTR of CHI3L1 (Suppl. Table S1). To investigate the miRNA-dependent regulation of CHI3L1 expression in TLR2- and TLR3-activated BEAS-2B cells, we first determined the abundance of these miRNAs in LTA, poly(I:C), or TNF- $\alpha$ stimulated cells via quantitative RT-PCR. Additionally, we investigated the involvement of NF- $\mathrm{kB}$ activation on this miRNA using BAY11-7082 inhibitor. As a control, we analysed miR-146a-5p, which is known to be upregulated upon an inflammatory stimulus [45].

As expected, our results revealed that miR-146a-5p was strongly upregulated post LTA, poly(I:C) and TNF- $\alpha$ stimulation with the strongest induction of 150-fold upon LTA treatment (Fig. 4A-C). Since miR-146a-5p is known to be activated via NF-кB [36], we also tested the expression of miR-146a-5p abundance upon BAY11-7082 inhibitor treatment (Fig. 4D). As anticipated, miR-146a-5p was strongly reduced by 10 -fold in inhibitor-treated, LTA- or poly(I:C)-stimulated cells compared to DMSO-treated cells. The expression of miRNAs miR-30d and miR-125a-3p did not change significantly in any tested conditions. Therefore, it was excluded that these miRNAs regulate TLR2- or TLR3dependent CHI3L1 expression in BEAS-2B cells (Suppl. Fig. S4). MiR24-3p, which was published to interact with CHI3L1 3'UTR in mice osteoblasts [38], was only significantly reduced post poly(I:C) stimulation (Fig. 4A-D). Interestingly, miRNA-149-5p abundance was strongly reduced in all tested conditions with a robust reduction down to $10 \%$ in poly(I:C)-stimulated cells (Fig. $4 \mathrm{~A}-\mathrm{C}$ ). This reduction was partially reversed back to 50\% using BAY11-7082 inhibitor compared to DMSO-treated cells (Fig. 4D). Comparable effects on miR-149-5p levels were detected in inhibitor-treated LTA-stimulated cells.

Taken together, TLR2 and TLR3 activation as well as TNF- $\alpha$ stimulation of BEAS-2B cells strongly reduced miR-149-5p expression, which was partially restored by inhibiting nuclear translocation of NF$\kappa B$. Notably, CHI3L1 upregulation correlates with miR-149-5p downregulation suggesting a regulatory function of miR-149-5p in CHI3L1 mRNA expression.

\subsection{MiR-149-5p directly targets the $3^{`}$ UTR of CHI3L1 and regulates expression of CHI3L1}

To investigate whether miR-149-5p targets the 3'UTR of CHI3L1, we performed luciferase reporter assays and transfected A549 cells with luciferase vectors containing different versions of the 3'UTR of CHI3L1 (Fig. 5A). In this regard, we also tried to perform luciferase reporter assay in BEAS-2B cell line, but very low detection of luciferase activity eliminated this option. The wildtype (WT) vector contained the whole CHI3L1 3'UTR (www.ensembl.org, release 95, 514 nucleotides, nt). In addition, we mutated three putative seed regions (seed positions 4-8 of miR-149-5p) within the 3'UTR of CHI3L1. To prevent predicted miRNA binding to the 3'UTR, Mutation (Mut) 1 vector was mutated for the first, Mut2 vector for the second and Mut3 vector for the third miR-149-5p seed region (Fig. 5A). Each vector version was co-transfected with the 


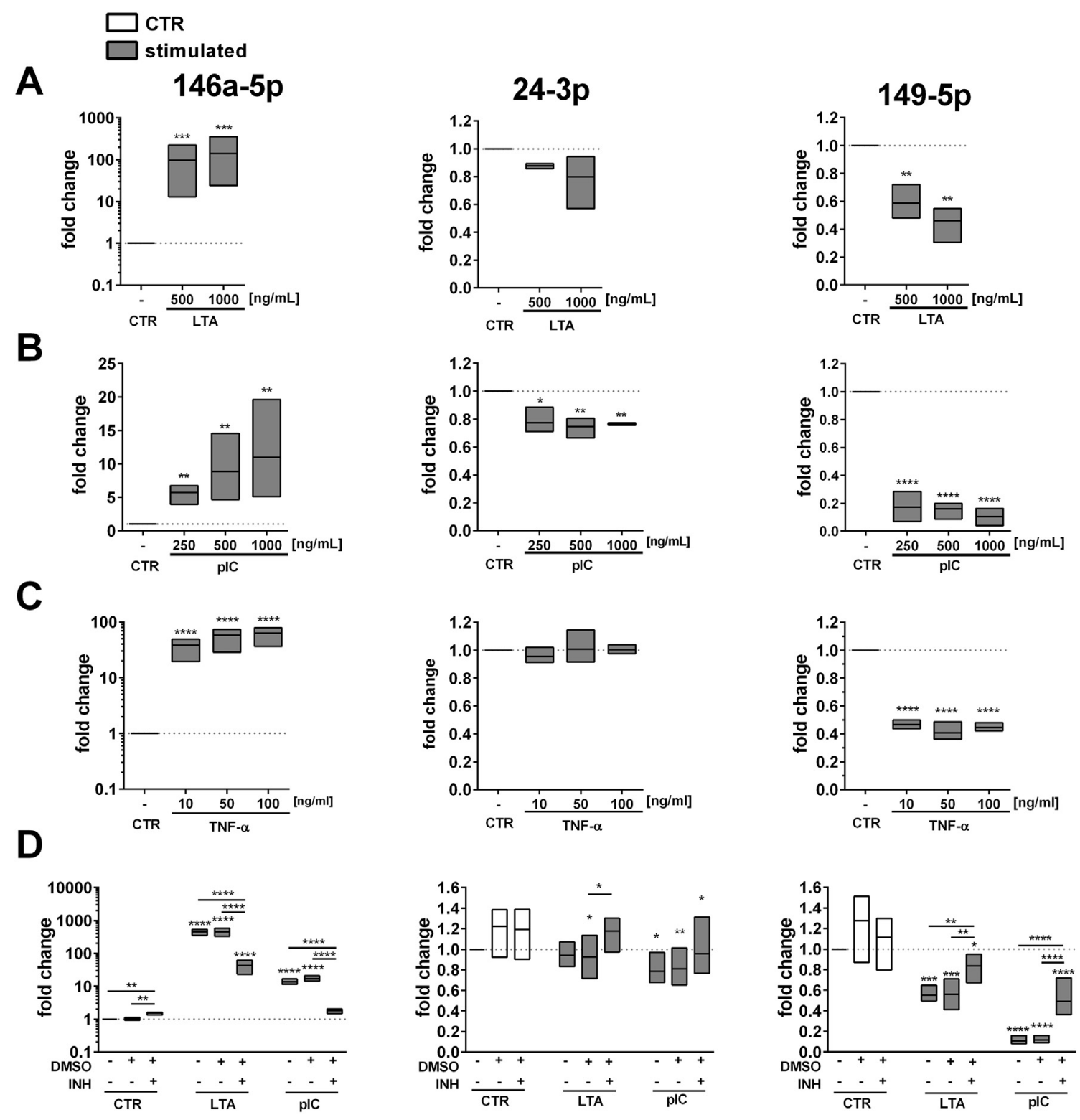

Fig. 4. NF-kB inhibition suppresses miRNA-149-5p reduction upon TLR2 and TLR3 activation in BEAS-2B cells. BEAS-2B cells were stimulated for $24 \mathrm{~h}$ with (A) LTA, (B) pIC, (C) TNF- $\alpha$ or left untreated as a control (CTR). In case of inhibitor experiments (D), BEAS-2B cells were pre-treated with DMSO (0.005\%) or BAY11-7082 $(5 \mu \mathrm{M}, \mathrm{INH})$ for $1 \mathrm{~h}$ prior to LTA $(1 \mu \mathrm{g} / \mathrm{mL})$ or pIC $(1 \mu \mathrm{g} / \mathrm{mL})$ stimulation for $24 \mathrm{~h}$ or left untreated as a control (right panel). Shown are quantitative RT-PCR analyses for determination of miR-146a-5p (left panel), miR-24-3p (middle panel) and miR-149-5p (right panel) abundances. Expression of miRNAs was normalized to endogenous RNU48 and unstimulated control. $N \geq 3$. Stats were calculated using $\log _{2}$-transformed data. Ordinary one-way ANOVA using Holm-Sidak multiple comparisons test (stimulation experiments); Two-way ANOVA using Holm-Sidak multiple comparisons test (inhibition experiments). ${ }^{*} p<.05$; $* * p<.01$; $* * * p<.001 ; * * * * p<.0001$. Shown are floating bars with line at mean.

mimic of miR-149-5p. As controls, we used the empty vector and the mimic negative control. Overexpression of miR-149-5p led to an approximately $35 \%$ reduction of luciferase activity using WT vector compared to mimic-control transfected samples (Fig. 5B). While Mut1 and Mut2 did not rescue the luminescence upon miR-149-5p transfection, Mut3 resulted in a complete luminescence recovery.

Having observed that miR-149-5p directly targets the 3'UTR of CHI3L1, we next investigated whether the absence or presence of miR149-5p function is responsible for regulation of CHI3L1 mRNA abundance. Therefore, we transfected BEAS-2B cells with miR-149-5p inhibitor or mimic and subsequently stimulated them with LTA. Analysis of miR-149-5p expression revealed a reduction down to $75 \%$ in untreated inhibitor transfected cells compared to control transfected cells (Fig. 6A). After LTA stimulation, control as well as miR-149-5p inhibited cells showed a strong reduction down to $40 \%$. In comparison,
CHI3L1 mRNA expression in unstimulated cells was increased upon miR-149-5p inhibition, which was further elevated after LTA stimulation up to 12-fold compared to a 9-fold induction in control transfected cells (Fig. 6B). This observation was further supported by a slight increase of CHI3L1 protein release in LTA stimulated cells (Fig. 6C). Vice versa, mimicking an overexpression of miR-149-5p showed a strong abundance of miR-149-5p that was not changed in response to LTA stimulation (Fig. 6D). CHI3L1 mRNA abundance in turn was strongly regulated down to 0.15 -fold in control-treated cells, while in LTA stimulated cells, CHI3L1 expression increased up to 1 -fold, but was still 10 -fold reduced compared to control transfected cells (Fig. 6E). In addition, CHI3L1 protein secretion was significantly reduced in miR-149$5 p$ overexpressed and LTA stimulated cells compared to control transfected cells (Fig. 6F).

As a control, we further examined the expression of CXCL8 mRNA 
A

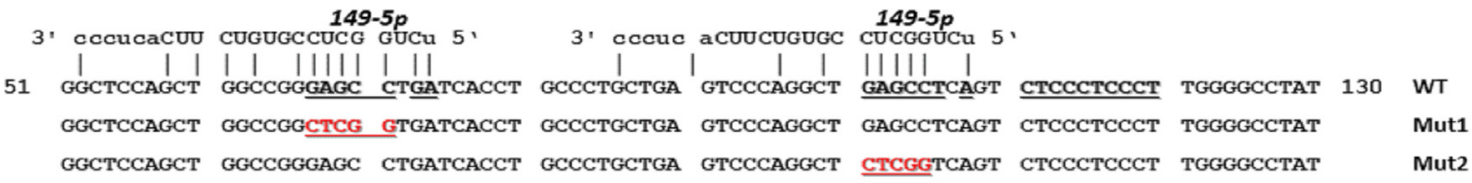

149-5p

3. cccuca CUUCUGUGCC UCGGUCu 5 ,

| | || || ||||| |

331 ACACCATTTT GGCAAGCTCT ATCACCAAGG AGCCAAACAT CCTACAAGAC ACAGTGACCA TACTAATTAT 400 WT

ACACCATTTT GGCAAGCTCT ATCACCAAGC TCGGAAACAT CCTACAAGAC ACAGTGACCA TACTAATTAT MUT3

B

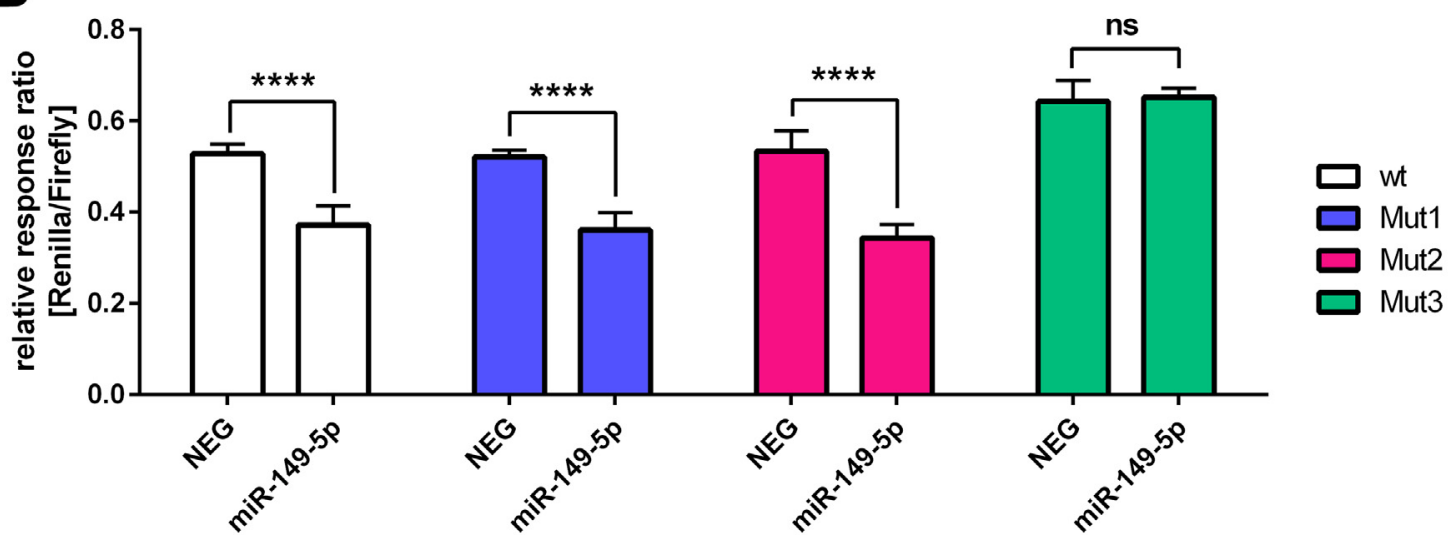

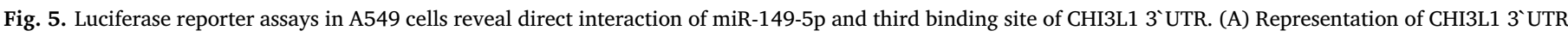

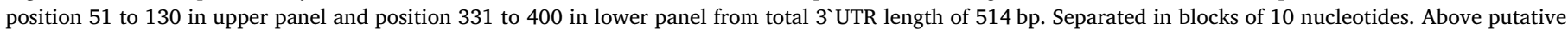

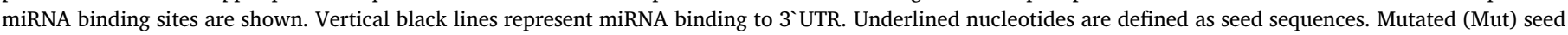

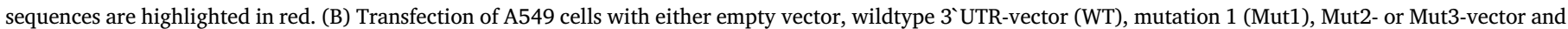

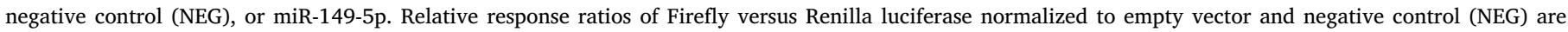

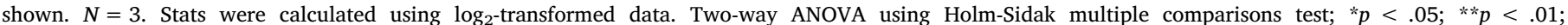

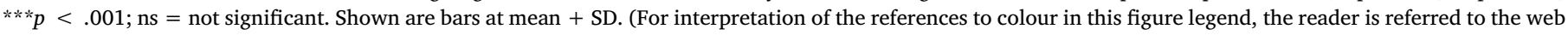
version of this article.)

and protein. Interestingly, under control conditions, CXCL8 mRNA expression was slightly upregulated in miRNA inhibitor-transfected cells and CXCL8 mRNA and protein were significantly downregulated in miRNA overexpressing cells (Suppl. Fig. 5). In LTA stimulated cells, CXCL8 protein expression was downregulated in miRNA-inhibited cells compared to control-transfected cells, while in miRNA-overexpressed cells CXCL8 mRNA expression was significantly increased. Additionally, we tested if CHI3L1 treatment influences expression levels of CXCL8 directly. Therefore, we treated BEAS-2B cells with recombinant CHI3L1 (rCHI3L1; $0.2-200 \mathrm{ng} / \mathrm{mL}$ ) for 4 and $24 \mathrm{~h}$. CHI3L1 treatment did not change viability of BEAS-2B cells as tested by lactate dehydrogenase assay (Suppl. Fig. S6A). As a control for a potential feedback loop, we determined CHI3L1 mRNA expression. After $4 \mathrm{~h}$, a significant increase in mRNA expression was observed in 20 and $200 \mathrm{ng} / \mathrm{mL}$ rCHI3L1 treated cells compared to mock treated cells (Suppl. Fig. S6B). For CXCL8 mRNA expression, a significant increase was examined after $24 \mathrm{~h}$ with $200 \mathrm{ng} / \mathrm{mL}$ rCHI3L1 (Suppl. Fig. S6C). However, this increased mRNA expression was not accompanied by increased CXCL8 protein expression (Suppl. Fig. S6D).

In summary, miR-149-5p directly targeted the CHI3L1 3'UTR as validated by downregulation of luciferase activity in luciferase reporter assays. Moreover, mutation of the third putative binding site of miR149-5p was sufficient to block the interaction with the CHI3L1 3'UTR. While inhibition of miR-149-5p induced the expression of CHI3L1 mRNA, overexpression of miR-149-5p strongly inhibited CHI3L1 mRNA expression. In addition, miR-149-5p overexpression enhanced CXCL8 expression in TLR2-activated cells, which was not dependent on CHI3L1 expression, but rather on miR-149-5p overexpression.

\section{Discussion}

Pneumonia causes high morbidity and mortality in humans and is the most frequent infectious cause of death in children under 5 years of age worldwide (World Health Organization, 2019, [46]). In this study, we focused on human respiratory epithelial cells that respond to lung infections caused by the toll-like receptors TLR2 and TLR3 signalling. Therefore, we investigated whether the antibacterial protein CHI3L1 is post-transcriptionally regulated by miR-149-5p upon TLR2 and TLR3 activation. Our data revealed that miR-149-5p is strongly downregulated in TLR2- and TLR3-activated airway epithelial cells to enable increased CHI3L1 expression. This effect further depends on TLRmediated NF- $\mathrm{KB}$ translocation into the nucleus. The regulatory potential of miR-149-5p and CHI3L1 is linked to a direct binding of miR-149-5p to the CHI3L1 3'UTR, which enables suppression of CHI3L1 expression and results in an increased inflammatory CXCL8 response.

Our studies revealed that miR-149-5p and CHI3L1 expression de-

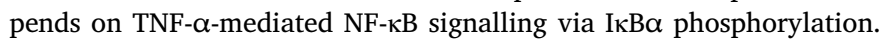
These results are consistent with the current knowledge about TLR2and TLR3-signalling pathways, which both, despite their different induction, induce translocation of NF- $\mathrm{kB}$ to the nucleus $[9,47,48]$. There, $\mathrm{NF}-\mathrm{kB}$ binds to promoter regions of several thousands of target genes to induce inflammatory responses [49,50]. In addition to induction of cytokines or chemokines such as CXCL8, also expression of the glycoprotein CHI3L1 is induced [22]. Thereby, CHI3L1 conducts diverse 
A

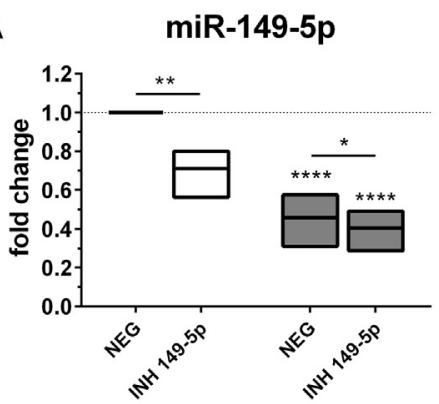

B
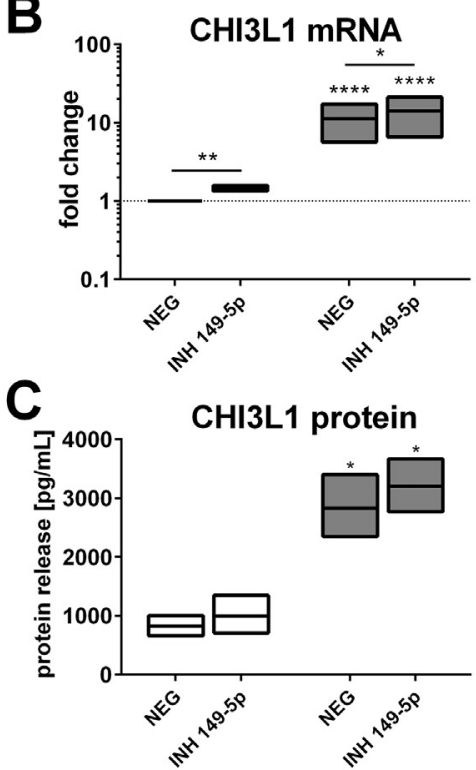

D

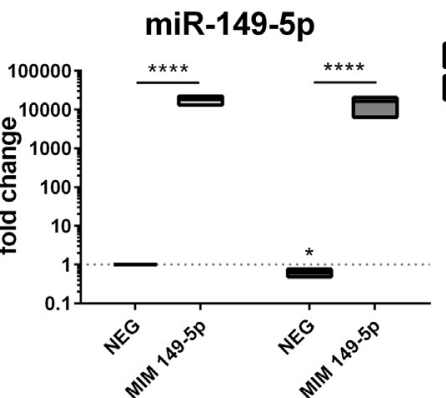

E

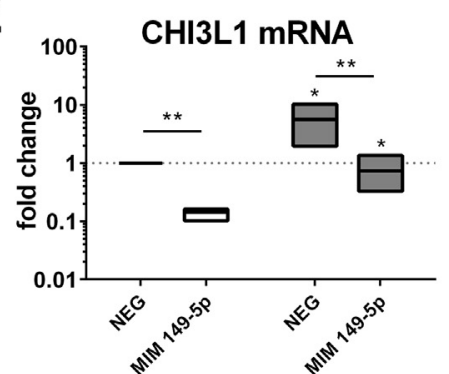

$\mathbf{F}$

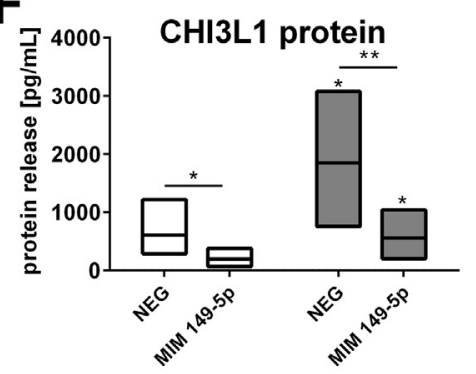

Fig. 6. Inhibition and overexpression of miR-149-5p correlates with expression levels of CHI3L1 in human bronchial epithelial cells. BEAS-2B cells were transfected with (A, B, E) miR-149-5p inhibitor (INH 149-5p), (C, D, F) miR-149-5p mimic (MIM-149-5p) or a negative control (NEG) for $24 \mathrm{~h}$ and stimulated with LTA $(1 \mu \mathrm{g} / \mathrm{mL})$ or mock-treated (CTR) for additional $24 \mathrm{~h}$. Quantification of expression of (A, C) miR149-5p, (B, D) CHI3L1 mRNA and (E, F) CHI3L1 protein release was performed using quantitative RT-PCR or ELISA, respectively. Expression was normalized to endogenous RNU48 for miRNA or GAPDH for mRNA and unstimulated control. $N=3-4$. Stats were calculated using $\log _{2}$-transformed data. Two-way ANOVA using Holm-Sidak multiple comparisons test. ${ }^{*} p<.05 ; \quad * * p<.01 ; * * * p<.001$; $* * * * p<.0001$. Shown are floating bars with line at mean. cellular functions that are important in a variety of cell types. Besides its function in proliferation and differentiation [51,52], especially its role in infection control was demonstrated. There, CHI3L1 counteracts invading bacteria in a murine bacterial lung infection model in macrophages as shown for Streptococcus pneumoniae, or is able to kill Candida albicans in mouse cornea infections [23,24].

Additionally to CHI3L1, the role of microRNAs in the regulation of post-transcriptional processes, e.g. in inflammatory diseases, has been intensively discussed in the last ten years. In the TLR-mediated inflammation model tested here, we identified miR-149-5p to be strongly downregulated in bronchial epithelial cells during TLR2 and TLR3 activation, as well as upon TNF- $\alpha$ stimulation. Expression of miR-149-5p was shown to be dependent on the expression of its host gene glypican1 (GPC1) [53], which itself is known to play a role in cell division and growth regulation as it might lead to cancer [54,55]. The same holds true for miR-149-5p. Downregulation of miR-149-5p is already associated with various diseases, e.g. in the liver epithelial cancer cell line NCI-N87, where miR-149-5p is called an anti-fitness miRNA due to its downregulation [56]. Thereby, expression of this miRNA is associated to tumour suppression, while its downregulation functions as biomarker for cancer [57]. However, only little is known regarding the function of miR-149-5p and its host gene GPC1 in inflammation: GPC1 was described to be upregulated in a bacterial infection of oral epithelial cells [58] and additionally, it was shown that miR-149-5p directly targets IL-6 (interleukin 6) in gastric cancer associated fibroblasts or MYD88 (myeloid differentiation primary response 88 ) in LPS-treated mouse macrophages $[59,60]$.

Here, we show for the first time a direct correlation between miR149-5p and CHI3L1 in respiratory epithelial cell inflammation upon TLR2, TLR3 and TNF- $\alpha$ signalling. Although it was demonstrated that TNF- $\alpha$ stimulation reduces the expression of miR-149-5p via $\mathrm{p} 38$ /
MAPK pathway in endothelial cells [61], our data indicated no reduction in CHI3L1 expression by inhibition of p38/MAPK or ERK1/2 in our current model, but by inhibition of NF- $\mathrm{KB}$ translocation. Thus, we speculate that TLR2- and TLR3-mediated down-regulation of miR-149$5 p$ and therefore activation of CHI3L1 expression in airway epithelial cells is mainly dependent on TNF- $\alpha$-mediated IKB $\alpha$ phosphorylation and degradation to enable NF- $\mathrm{\kappa B}$ translocation.

In this study, we provide evidence that overexpression of miR-149$5 \mathrm{p}$ and thus the absence of CHI3L1 mRNA under TLR2 activation in bronchial epithelial cells led to an increased CXCL8 expression. CHI3L1 addition itself to bronchial epithelial cells was not clearly able to induce CXCL8 expression, which might depend on kinetic shifts. CXCL8 was shown to be upregulated through CHI3L1 in human bronchial epithelial cells leading to muscle cell proliferation [62]. Besides that, miR-149-5p has been shown to interact with MYD88 to block its expression [60]. This would theoretically eliminate the MYD88-dependent signalling necessary for TLR2-mediated NF-KB activation to induce CXCL8 expression $[63,64]$. However, CHI3L1 treatment reduced CXCL8 expression in a TNF- $\alpha$-dependent manner in skeletal muscle cells [65], pointing towards contradictory observations regarding CHI3L1-dependent regulation of CXCL8 expression. Thus, the enhancement of cytokine expression in miR-149-5p overexpressed and TLR2-activated cells is not yet explicable and ought to be the focus of follow-up studies.

\section{Conclusions}

In conclusion, we identified an upregulation of CHI3L1 and a downregulation of miR-149-5p in TLR2, TLR3- and TNF- $\alpha$-activated human bronchial epithelial cells. This regulatory effect was partially dependent on TNF- $\alpha$-mediated activation of NF-кB. While miR-149-5p directly interacts with the 3`UTR of CHI3L1, inhibition and 
overexpression of miR-149-5p changed expression levels of CHI3L1 mRNA in bronchial epithelial cells. Altogether, our findings underline a tight and interconnected regulatory network of inflammation-mediated signalling and miRNA function on CHI3L1 in human bronchial epithelial cells, providing a potential target for therapeutic interventions.

Supplementary data to this article can be found online at https:// doi.org/10.1016/j.cellsig.2019.109498.

\section{Declaration of Competing Interest}

None.

\section{Acknowledgements}

We are grateful to Ronny Kellner for comments on the manuscript and thank all laboratory members for valuable discussions.

This work has been funded in part by the Bundesministerium für Bildung und Forschung (Federal Ministry of Education and Research, JPI-AMR - FKZ 01KI1702; ERACoSysMed2 - SysMed-COPD - FKZ 031L0140; e:Med CAPSYS - FKZ 01ZX1604E), the Deutsche Forschungsgemeinschaft (SFB/TR84 TRR84/3), the Von-BehringRöntgen-Stiftung (66-LV07), and the Hessisches Ministerium für Wissenschaft und Kunst (LOEWE Medical RNomics 519/03/00.001[0003]) to B. S. The funding sources were not involved in the study.

\section{References}

[1] C. Feldman, R. Anderson, The role of Streptococcus pneumoniae in communityacquired pneumonia, Semin Respir Crit Care Med 37 (6) (2016) 806-818.

[2] C. Peteranderl, S. Herold, C. Schmoldt, Human influenza virus infections, Semin Respir Crit Care Med 37 (4) (2016) 487-500.

[3] R. Medzhitov, C. Janeway Jr., Innate immunity, N. Engl. J. Med. 343 (5) (2000) 338-344.

[4] A. Ray, et al., Bacterial cell wall macroamphiphiles: pathogen -/microbe-associated molecular patterns detected by mammalian innate immune system, Biochimie 95 (1) (2013) 33-42.

[5] M. Yu, S.J. Levine, Toll-like receptor, RIG-I-like receptors and the NLRP3 inflammasome: key modulators of innate immune responses to double-stranded RNA viruses, Cytokine Growth Factor Rev. 22 (2) (2011) 63-72.

[6] J. Krishnan, et al., Toll-like receptor signal transduction, Exp. Mol. Med. 39 (4) (2007) 421-438.

[7] G. Zhao, et al., Polydatin reduces Staphylococcus aureus lipoteichoic acid-induced injury by attenuating reactive oxygen species generation and TLR2-NF kappa B signalling, J. Cell. Mol. Med. 21 (11) (2017) 2796-2808.

[8] B. Schmeck, et al., Pneumococci induced TLR- and Rac1-dependent NF-kappaBrecruitment to the IL-8 promoter in lung epithelial cells, Am. J. Phys. Lung Cell. Mol. Phys. 290 (4) (2006) L730-L737.

[9] T. Shuto, et al., Activation of NF-kappa B by nontypeable Hemophilus influenzae is mediated by toll-like receptor 2-TAK1-dependent NIK-IKK alpha /beta-I kappa B alpha and MKK3/6-p38 MAP kinase signaling pathways in epithelial cells, Proc. Natl. Acad. Sci. U. S. A. 98 (15) (2001) 8774-8779.

[10] Y. Wang, et al., Dimerization of toll-like receptor 3 (TLR3) is required for ligand binding, J. Biol. Chem. 285 (47) (2010) 36836-36841.

[11] M. Tatematsu, T. Seya, M. Matsumoto, Beyond dsRNA: toll-like receptor 3 signalling in RNA-induced immune responses, Biochem. J. 458 (2) (2014) 195-201.

[12] F.D. Coffman, Chitinase 3-Like-1 (CHI3L1): a putative disease marker at the interface of proteomics and glycomics, Crit. Rev. Clin. Lab. Sci. 45 (6) (2008) 531-562.

[13] M. Prakash, et al., Diverse pathological implications of YKL-40: answers may lie in 'outside-in' signaling, Cell. Signal. 25 (7) (2013) 1567-1573.

[14] S. Libreros, R. Garcia-Areas, V. Iragavarapu-Charyulu, CHI3L1 plays a role in cancer through enhanced production of pro-inflammatory/pro-tumorigenic and angiogenic factors, Immunol. Res. 57 (1-3) (2013) 99-105.

[15] M.H. Kazakova, et al., YKL-40 and cytokines - a new diagnostic constellation in rheumatoid arthritis? Folia Med (Plovdiv) 59 (1) (2017) 37-42.

[16] C. Hobaus, et al., YKL-40 levels increase with declining ankle-brachial index and are associated with long-term cardiovascular mortality in peripheral arterial disease patients, Atherosclerosis 274 (2018) 152-156.

[17] B.E. Hakala, C. White, A.D. Recklies, Human cartilage gp-39, a major secretory product of articular chondrocytes and synovial cells, is a mammalian member of a chitinase protein family, J. Biol. Chem. 268 (34) (1993) 25803-25810.

[18] D. Low, et al., High endogenous expression of Chitinase 3-like 1 and excessive epithelial proliferation with colonic tumor formation in MOLF/EiJ mice, PLoS One 10 (10) (2015) e0139149.

[19] D. Low, et al., Chitinase 3-like 1 induces survival and proliferation of intestinal epithelial cells during chronic inflammation and colitis-associated cancer by regulating S100A9, Oncotarget 6 (34) (2015) 36535-36550.

[20] L. Maegdefessel, et al., miR-24 limits aortic vascular inflammation and murine abdominal aneurysm development, Nat. Commun. 5 (2014) 5214.

[21] M. Kawada, et al., Chitinase 3-like-1 enhances bacterial adhesion to colonic epithelial cells through the interaction with bacterial chitin-binding protein, Lab. Investig. 88 (8) (2008) 883-895.

[22] R. Bhardwaj, et al., RelB/p50 complexes regulate cytokine-induced YKL-40 expression, J. Immunol. 194 (6) (2015) 2862-2870.

[23] C.S. Dela Cruz, et al., Chitinase 3-like-1 promotes Streptococcus pneumoniae killing and augments host tolerance to lung antibacterial responses, Cell Host Microbe 12 (1) (2012) 34-46.

[24] N. Gao, F.S. Yu, Chitinase 3-like 1 promotes Candida albicans killing and preserves corneal structure and function by controlling host antifungal responses, Infect. Immun. 83 (10) (2015) 4154-4164.

[25] Y. Zhou, et al., Chitinase 3-like 1 suppresses injury and promotes fibroproliferative responses in mammalian lung fibrosis, Sci. Transl. Med. 6 (240) (2014) 240 ra76.

[26] D.P. Bartel, MicroRNAs: genomics, biogenesis, mechanism, and function, Cell 116 (2) (2004) 281-297.

[27] J. O'Brien, et al., Overview of MicroRNA biogenesis, mechanisms of actions, and Circulation, Front Endocrinol (Lausanne) 9 (2018) 402.

[28] J. Han, et al., The Drosha-DGCR8 complex in primary microRNA processing, Genes Dev. 18 (24) (2004) 3016-3027.

[29] Y. Lee, et al., The nuclear RNase III Drosha initiates microRNA processing, Nature 425 (6956) (2003) 415-419.

[30] A.M. Denli, et al., Processing of primary microRNAs by the microprocessor complex, Nature 432 (7014) (2004) 231-235.

[31] R.I. Gregory, et al., The microprocessor complex mediates the genesis of microRNAs, Nature 432 (7014) (2004) 235-240.

[32] M. Landthaler, A. Yalcin, T. Tuschl, The human DiGeorge syndrome critical region gene 8 and its D. melanogaster homolog are required for miRNA biogenesis, Curr. Biol. 14 (23) (2004) 2162-2167.

[33] S. Bagga, et al., Regulation by let-7 and lin-4 miRNAs results in target mRNA degradation, Cell 122 (4) (2005) 553-563.

[34] L.P. Lim, et al., Microarray analysis shows that some microRNAs downregulate large numbers of target mRNAs, Nature 433 (7027) (2005) 769-773.

[35] R.S. Pillai, S.N. Bhattacharyya, W. Filipowicz, Repression of protein synthesis by miRNAs: how many mechanisms? Trends Cell Biol. 17 (3) (2007) 118-126.

[36] K.D. Taganov, et al., NF-kappaB-dependent induction of microRNA miR-146, an inhibitor targeted to signaling proteins of innate immune responses, Proc. Natl. Acad. Sci. U. S. A. 103 (33) (2006) 12481-12486.

[37] N.J. Sarma, et al., Hepatitis C virus mediated changes in miRNA-449a modulates inflammatory biomarker YKL40 through components of the NOTCH signaling pathway, PLoS One 7 (11) (2012) e50826.

[38] T. Jin, et al., The role of MicroRNA, miR-24, and its target CHI3L1 in osteomyelitis caused by Staphylococcus aureus, J. Cell. Biochem. 116 (12) (2015) 2804-2813.

[39] Z. Jingjing, et al., MicroRNA-24 modulates Staphylococcus aureus-induced macrophage polarization by suppressing CHI3L1, Inflammation 40 (3) (2017) 995-1005.

[40] M. Hashimoto, et al., Not lipoteichoic acid but lipoproteins appear to be the dominant immunobiologically active compounds in Staphylococcus aureus, J. Immunol. 177 (5) (2006) 3162-3169.

[41] K.J. Livak, T.D. Schmittgen, Analysis of relative gene expression data using real time quantitative PCR and the 2(-Delta Delta C(T)) method, Methods 25 (4) (2001) 402-408.

[42] M. Hashimoto, et al., Not lipoteichoic acid but lipoproteins appear to be the dominant immunobiologically active compounds in Staphylococcus aureus, J. Immunol. 177 (5) (2006) 3162-3169.

[43] A.K. Field, et al., Inducers of interferon and host resistance. II. Multistranded synthetic polynucleotide complexes, Proc. Natl. Acad. Sci. U. S. A. 58 (3) (1967) 1004-1010.

[44] J.W. Pierce, et al., Novel inhibitors of cytokine-induced IkappaBalpha phosphorylation and endothelial cell adhesion molecule expression show anti-inflammatory effects in vivo, J. Biol. Chem. 272 (34) (1997) 21096-21103.

[45] E.M. Quinn, et al., MicroRNA-146a is upregulated by and negatively regulates TLR2 signaling, PLoS One 8 (4) (2013) e62232.

[46] https://www.who.int/news-room/fact-sheets/detail/pneumonia (2nd August 2019).

[47] E. Meylan, et al., RIP1 is an essential mediator of toll-like receptor 3-induced NFkappa B activation, Nat. Immunol. 5 (5) (2004) 503-507.

[48] V. Tergaonkar, et al., Distinct roles of IkappaB proteins in regulating constitutive NF-kappaB activity, Nat. Cell Biol. 7 (9) (2005) 921-923.

[49] S. Saccani, S. Pantano, G. Natoli, p38-dependent marking of inflammatory genes for increased NF-kappa B recruitment, Nat. Immunol. 3 (1) (2002) 69-75.

[50] S. Saccani, S. Pantano, G. Natoli, Two waves of nuclear factor kappaB recruitment to target promoters, J. Exp. Med. 193 (12) (2001) 1351-1359.

[51] Recklies, A.D., C. White, and H. Ling, The chitinase 3-like protein human cartilage glycoprotein 39 (HC-gp39) stimulates proliferation of human connective-tissue cells and activates both extracellular signal-regulated kinase- and protein kinase Bmediated signalling pathways. Biochem. J., 2002. 365(Pt 1): p. 119-26.

[52] S. Scully, et al., Inhibitory activity of YKL-40 in mammary epithelial cell differentiation and polarization induced by lactogenic hormones: a role in mammary tissue involution, PLoS One 6 (10) (2011) e25819.

[53] A. Chamorro-Jorganes, et al., Autoregulation of glypican-1 by intronic microRNA149 fine tunes the angiogenic response to FGF2 in human endothelial cells, J. Cell Sci. 127 (Pt 6) (2014) 1169-1178.

[54] J. Li, et al., Glypican-1 promotes tumorigenesis by regulating the PTEN/Akt/betacatenin Signaling pathway in Esophageal squamous cell carcinoma, Dig. Dis. Sci. 64 (6) (2019) 1493-1502. 
[55] D. Qiao, et al., Glypican-1 regulates anaphase promoting complex/cyclosome substrates and cell cycle progression in endothelial cells, Mol. Biol. Cell 19 (7) (2008) 2789-2801.

[56] J.S. Kurata, R.J. Lin, MicroRNA-focused CRISPR-Cas9 library screen reveals fitnessassociated miRNAs, RNA 24 (7) (2018) 966-981.

[57] Y. He, et al., miR-149 in Human Cancer: A Systemic Review, J. Cancer 9 (2) (2018) 375-388.

[58] G. Zhang, J.D. Rudney, Streptococcus cristatus attenuates Fusobacterium nucleatum-induced cytokine expression by influencing pathways converging on nuclear factor-kappaB, Mol Oral Microbiol 26 (2) (2011) 150-163.

[59] P. Li, et al., Epigenetic silencing of microRNA-149 in cancer-associated fibroblasts mediates prostaglandin E2/interleukin-6 signaling in the tumor microenvironment, Cell Res. 25 (5) (2015) 588-603.

[60] G. Xu, et al., MicroRNA-149 negatively regulates TLR-triggered inflammatory response in macrophages by targeting MyD88, J. Cell. Biochem. 115 (5) (2014) 919-927.
[61] D. Palmieri, et al., TNFalpha induces the expression of genes associated with endothelial dysfunction through p38MAPK-mediated down-regulation of miR-149, Biochem. Biophys. Res. Commun. 443 (1) (2014) 246-251.

[62] H. Tang, et al., YKL-40 induces IL-8 expression from bronchial epithelium via MAPK (JNK and ERK) and NF-kappaB pathways, causing bronchial smooth muscle proliferation and migration, J. Immunol. 190 (1) (2013) 438-446.

[63] O. Takeuchi, K. Hoshino, S. Akira, Cutting edge: TLR2-deficient and MyD88-deficient mice are highly susceptible to Staphylococcus aureus infection, J. Immunol. 165 (10) (2000) 5392-5396.

[64] O. Takeuchi, et al., Cellular responses to bacterial cell wall components are mediated through MyD88-dependent signaling cascades, Int. Immunol. 12 (1) (2000) 113-117.

[65] S.W. Gorgens, et al., Chitinase-3-like protein 1 protects skeletal muscle from TNFalpha-induced inflammation and insulin resistance, Biochem. J. 459 (3) (2014) $479-488$. 